\title{
STIMULASI DAKWAH MENUJU MASYARAKAT QUR'ANI MELALUI KKN STIBA MAKASSAR DI DESA ALATENGAE KABUPATEN MAROS
}

\author{
Khaerul Aqbar \\ Sekolah Tinggi Ilmu Islam dan Bahasa Arab (STIBA) Makassar \\ khaerul@stiba.ac.id \\ Putra Alam \\ Sekolah Tinggi Ilmu Islam dan Bahasa Arab (STIBA) Makassar \\ putra@stiba.ac.id
}

\begin{abstract}
Keywords :
Community Service, KKN,

Alatengae Village, Islamic

knowledge, and STIBA

Makassar

Alatengae Village on the basis of history is attached to the noble goals and ideals to always act and intend towards a better direction. The purpose of STIBA Makassar Community Service Program (KKN) III is as a form of community service which is a pillar of higher education tri dharma. The method of community service implementation in Alatengae Village began with an analysis of problems or community needs through SOAR analysis and independently created instruments. After the analysis carried out, an activity plan program was prepared which was adaptive to the needs of the community. The main program of students of STIBA Makassar Community Service Program (KKN) III in Alatengae Village were to build relation between people, teaching in elementary schools, or TK/TPA, Dirosa teaching, Islamic discouce for men and women, Tablig Akbar, Health and Cupping Seminar, and Festival for Righteous Children (FAS). The results of Community Service implementation in the form of KKN is that, in general, local people has developed in terms of Islamic knowledge, are enthusiastic in learning and has been able to read the Koran correctly, and the growth of self-confidence of students in TK/TPA in competing and high enthusiasm in enhancing interest and talent.
\end{abstract}

\footnotetext{
Kata kunci :

Pengabdian Masyarakat, KKN, Desa Alatengae, Pengetahuan Islam, dan STIBA Makassar
} 
Muslimah, Tablig Akbar, Seminar Kesehatan dan Bekam, dan Festival Anak Saleh (FAS). Adapun hasil dari pelaksanaan PkM berwujud KKN ini ialah pada umumnya masyarakat setempat mengalami perkembangan dari sisi pengetahuan keislaman, antusias dalam mempelajari dan telah mampu membaca al-Qur'an dengan baik dan benar, dan tumbuhnya kepercayaan diri pada diri santri TK/TPA dalam berkompetisi dan antusiasme yang tinggi pada peningkatan minat dan bakat.

\section{PENDAHULUAN}

Desa Alatengae sejak keberadaannya sudah pernah mengalami pemekaran desa menjadi 2 (dua) wilayah desa yaitu: Desa Alatengae sebagai desa induk dan Desa Mattoangin sebagai desa pemekaran. Awalnya, Desa Alatengae terdiri dari 6 (enam) dusun, akan tetapi karena kebutuhan masyarakat saat ini dimekarkan lagi menjadi 8 (delapan) dusun. Alatengae bila dalam bahasa Indonesia mengandung arti menuju kebaikan. Desa Alatengae dikenal sebagai tempat situs bersejarah Arung Loe dimana Raja I (pertama) di Kabupaten Maros yang berkedudukan di Bulusipong. Bulusipong adalah salah satu dusun yang saat ini menjadi pusat pemerintahan Desa Alatengae Kecamatan Bantimurung Kabupaten Maros.

Dari nama Desa Alatengae terdapat makna akan tujuan dan cita-cita yang sangat mulia untuk selalu berbuat, berniat ke arah yang lebih baik, namun, titipan sejarah ini tentu tidak mudah sehingga menjadi tantangan dan kewajiban kita semua khususnya warga Desa Alatengae. Dari Desa Alatengae diharapkan lahir pemimpin-pemimpin di masa mendatang yang mempunyai karakter yang rajin dan tidak mengenal lelah demi desa yang sesuai dengan pernyataan awal mula terjadinya desa tersebut. Dari sekilas sejarah singkat Desa Alatengae benarlah citacita yang berbunyi bahwa desa-desa yang besar adalah desa yang bisa menghargai dan memelihara sejarah dan adat istiadat masyarakatnya, sehingga kelak yakin desa kita akan menjadi yang besar dan Desa Alatengae khususnya akan menjadi desa yang maju, makmur serta damai.

Warga Desa Alatengae sebagian besar hidup bekerja di sektor pertanian, usaha ternak sapi, itik dan ayam. Semua diusahakan secara tradisional, di daerah topografi yang datar. Hanya sedikit diantaranya yang bekerja di kantor pemerintah. Latar belakang pendidikan masyarakatnya juga masih sangat rendah. Hanya sekitar 3 persen di antaranya yang bergelar sarjana, sebagian besar hanya mengenyam pendidikan sampai Sekolah Menengah Pertama dan Sekolah Menengah Atas. Secara administrasi wilayah desa Alatengae memiliki luas wilayah 29,25 km², jarak dari ibukota kabupaten $5 \mathrm{~km}$, dan jarak dari ibukota kecamatan $4 \mathrm{~km}$. Adapun batas administrasi desa Alatengae, meliputi: 
WAHATUL MUJTAMA': Jurnal Pengabdian Masyarakat

Vol. 1, No. 2 (2020) : Hal. 209-221

Website: https://journal.stiba.ac.id

1. Sebelah barat: berbatasan dengan Desa Mattoangin

2. Sebelah selatan: berbatasan dengan Desa Minasa Baji

3. Sebelah utara: berbatasan dengan Desa Tanete Kecamatan Simbang

4. Sebelah timur: berbatasan dengan Kelurahan Boribellaya Kecamatan Turikale.

Adapun iklim desa Alatengae adalah beriklim tropis, sebagaimana desa-desa lain di wilayah Indonesia yang mempunyai iklim kemarau dan penghujan. Hal tersebut mempunyai pengaruh langsung terhadap pola tanam yang ada di Desa Alatengae Kecamatan Bantimurung.

\section{Profil Potensi Lokal}

Desa Alatengae mempunyai jumlah penduduk 5.102Jiwa dari 1.447 kartu keluarga, dengan asumsi jumlah penduduk laki-laki 2.519 jiwa dan perempuan sebanyak 2.583 jiwa yang tersebar di delapan dusun.

Pendidikan merupakan suatu hal yang memiliki peran penting dalam kehidupan. Salah satu peran pendidikan adalah pembentukan pola pikir dalam pengembangan kualitas hidup masyarakat. Kualitas pendidikan harus ditunjang dengan ketersediaan sarana dan prasarana pendidikan yang bermutu. Sarana pendidikan di Desa Alatengae terdiri dari 2 TK dan 3 Sekolah Dasar (SD), sebagai berikut:

\begin{tabular}{lll}
\hline No & Pendidikan & Dusun \\
\hline 1 & TK RA Pakalli & Pakalli \\
\hline 2 & TK & Bulusipong \\
& Dharmawanita & \\
\hline 3 & SDN 105 Inpres & Bulusipong \\
& Alatengae & \\
\hline 4 & SDN 231 Inpres & Tanah \\
& Tanah Tekko & Takko \\
\hline 5 & SDN 12 Pakalli I & Pakalli \\
\hline
\end{tabular}

Sumber: Profil Desa Alatengae Tahun 2019.

Sarana peribadatan adalah hal yang penting dalam kehidupan bermasyarakat oleh karena sarana ini merupakan tempat untuk mengisi kebutuhan rohani masyarakat. Untuk itu masyarakat perlu disediakan di lingkungan pedesaannya, namun, hal ini tidak mudah untuk langsung dibangunkan tempat peribadatan. Harus sesuai ketetapan, peraturan dan keputusan masyarakat yang bersangkutan. Dalam hal keagamaan penduduk Desa Alatengae sebagian besar menganut agama Islam. Adapun sarana keagamaan/ kerohanian di Desa Alatengae hanya terdiri dari sarana peribadatan berupa Mesjid yang datanya meliputi sebagai berikut:

No Masjid Dusun


WAHATUL MUJTAMA': Jurnal Pengabdian Masyarakat

Vol. 1, No. 2 (2020) : Hal. 209-222

Website: https://journal.stiba.ac.id

\begin{tabular}{lll}
\hline 1 & $\begin{array}{l}\text { Masjid Babut } \\
\text { Taubah }\end{array}$ & Gollae \\
\hline 2 & $\begin{array}{l}\text { Masjid Babul } \\
\text { Jama'ah }\end{array}$ & Bulusipong \\
\hline 3 & $\begin{array}{l}\text { Masjid Babul } \\
\text { Jannah }\end{array}$ & Pakalli \\
\hline 4 & $\begin{array}{l}\text { Masjid Babul } \\
\text { Rahman }\end{array}$ & Baramamase \\
\hline 5 & Masjid Babul & Bontobua \\
& Falah & \\
\hline 6 & $\begin{array}{l}\text { Masjid Nurul } \\
\text { Kautsar }\end{array}$ & Manjalling \\
\hline 7 & $\begin{array}{l}\text { Masjid Babul } \\
\text { Karim }\end{array}$ & Tanetea \\
\hline 8 & Masjid Babul & Tanah Takko \\
& Khaerat & \\
\hline
\end{tabular}

Sumber: Profil Desa Alatengae Tahun 2019.

Desa Alatengae juga memiliki beberapa unit sarana kesehatan yaitu: Poskesdes terdiri dari 1 unit; Posyandu terdiri dari 6 unit; Rumah Bersalin terdiri dari 1 unit. Sementara Keadaan penduduk berdasarkan mata pencaharian dapat digambarkan sebagai kehidupan sosial ekonomi dari sumber masyarakat tersebut. Untuk pekerjaan/ profesi masyarakat Desa Alatengae berdasarkan data 2019 adalah:

\begin{tabular}{lll}
\hline No & $\begin{array}{l}\text { Pekerjaan/ } \\
\text { Profesi }\end{array}$ & Jumlah \\
\hline 1 & Petani & 1300 \\
\hline 2 & Buruh Tani & 39 \\
\hline 3 & Buruh Pabrik & 49 \\
\hline 4 & PNS & 45 \\
\hline 5 & Pegawai Swasta & 74 \\
\hline 6 & Wiraswasta/ & 386 \\
& Pedagang & \\
\hline 7 & TNI & 3 \\
\hline 8 & Polri & 7 \\
\hline 9 & Bidan & 4 \\
\hline 10 & Perawat & 8 \\
\hline
\end{tabular}

Sumber: Profil Desa Alatengae Tahun 2019.

Berdasarkan profil desa dan potensi lokal Desa Alatengae di atas, maka untuk upaya pelaksanaan program kerja Kuliah Kerja Nyata (KKN) angkatan III STIBA Makassar, terlebih dahulu dilacak masalah dan kebutuhan program masyarakat Alatengae. Sebelum itu, ditetapkan tujuan dari pelaksanaan pengabdian kepada masyarakat berwujud KKN angkatan III STIBA Makassar ini di Desa Alatengae yaitu: 
WAHATUL MUJTAMA': Jurnal Pengabdian Masyarakat

Vol. 1, No. 2 (2020) : Hal. 209-222

Website: https://journal.stiba.ac.id

1. Mengaktualisasikan hasil belajar mahasiswa di masyarakat luas.

2. Memberikan kontribusi riil kepada masyarakat sebagai wujud realisasi pengamalan pilar tri dharma perguruan tinggi.

3. Menjadi ajang belajar dan evaluasi diri bagi mahasiswa dalam menghadapi dunia dakwah yang sesungguhnya.

4. Menjadi bahan evaluatif bagi STIBA Makassar dalam berbenah dan meningkatkan kualitas lulusan.

Adapun melalui instrumen mandiri ditemukan masalah fundamental masyarakat Alatengae yakni minimnya ilmu pengetahuan agama di masyarakat sehingga berdampak langsung kehidupan keseharian. Pada realita masyarakat ditemukan masih maraknya pelaksanakan ritual kesyirikan (seperti tolak bala, mappalili, dan mappasili kandungan), jumlah jemaah yang relatif sedikit di setiap masjid, dan tidak tangung-tanggung, kebersihan sarana dan prasarana masjid kurang dipedulikan oleh warga sekitar.

Analisis SOAR juga diterapkan guna menunjang strategi penyusunan program kerja KKN angkatan III STIBA Makassar di Desa Alatengae. Sajian sederhana analisis SOAR sebagai berikut:

1. Strength: Mayoritas masyarakat Alatengae memeluk agama Islam dan didukung oleh potensi falsafah hidup pedesaan berkarakter positif dan progresif.

2. Oppurtunities: Mahasiswa KKN STIBA Makassar merupakan aset yang siap dimanfaatkan selama kurang lebih 45 (empat puluh lima hari) masa pengabdian di Desa Alatengae. Disamping peluang kerjasama dakwah dapat dijalin dengan ormas keislaman Wahdah Islamiyah yang terbilang sebagai salah satu ormas yang cukup eksis di Kabupaten Maros, dan termasuk sering menjalin kerjasama dengan STIBA Makassar. Selain itu, dukungan penuh diberikan oleh Bapak Camat Bantimurung terhadap agenda kegiatan bersifat dakwah Islamiyah dan pengembangan masyarakat.

3. Aspiration: Berdasarkan kekuatan dan peluang yang ada, maka program kerja keislaman atau dakwah yang terstruktur yang sifatnya bersentuhan langsung dengan masyarakat sangat dibutuhkan di Desa Alatengae.

4. Result: Program kerja dakwah yang dinilai urgen dan adaptif di masyarakat adalah dimulai dengan silaturahim warga sebagai ajang pengenalan diri dan eksistensi keberadaan mahasiswa KKN STIBA Makassar, lalu diadakan dengar pendapat warga untuk kemudian dibuatkan skala prioritas dan porsi lebih banyak ihwal pelaksanaan program kerja.

Metode pelaksanaan PkM berbentuk KKN STIBA Makassar di Desa Alatengae berbentuk beberapa kegiatan utama di antaranya: Silaturahim Warga, Pengajaran di SD/TK/TPA, Pengajaran Dirosa, Taklim Muslim dan Muslimah, Tablig Akbar, Seminar Kesehatan dan Bekam, dan Festival Anak Saleh (FAS). Hasil-Hasil pengabdian kepada masyarakat $(\mathrm{PkM})$ terdahulu dan relevan dengan PkM berbentuk KKN STIBA Makassar di Desa Alatengae yang berhasil di-trace yaitu sebagai berikut: 
WAHATUL MUJTAMA': Jurnal Pengabdian Masyarakat

Vol. 1, No. 2 (2020) : Hal. 209-222

Website: https://journal.stiba.ac.id

1. PkM yang dilakukan oleh Surahma, dkk., ihwal kerja sama pelaksanaan program KKN antara Universitas Ahmad Dahlan dan Pemerintah Kecamatan Patuk dalam mengentaskan problem masyarakat yang banyak terlilit piutang rentenir, hasilnya adalah masyarakat memiliki tambahan pengetahuan dan keterampilan untuk pengembangan unit usaha dengan memanfaatkan potensi lokal. ${ }^{1}$

2. PkM yang dilakukan oleh Safar, dkk., terkait pelaksanaan program KKN-PPM dalam bentuk pelatihan di Desa Lagego, menunjukkan hasil bahwa pelatihan dan kegiatan pendukung acara pertandingan 17 Agustus, pembinaan TPA dan Majelis Taklim pada masyarakat Desa Lagego, Kecamatan Burau, Kabupaten Luwu Timur berdampak pada peningkatan pengetahuan, sikap dan keterampilan. ${ }^{2}$

3. PkM yang dilakukan oleh Maemunah, dkk., perihal pelaknsanaan program tematik KKN di Desa Bojong Rangkas, menunjukkan hasil bahwa masyarakat Desa, khususnya warga kampung pangkalan dua telah memahami akan pentingnya pendidikan, kesehatan dan teknologi. ${ }^{3}$

4. PkM yang dilakukan oleh Dyah, dkk., ihwal kegiatan KKN-BBM yang dilaksanakan di Desa Talun. Kegiatan dimulai dari survei lapangan kemudian dilanjutkan dengan sosialisasi, penyusunan program kerja bersama tokoh masyarakat, pembuatan proposal program kerja dan pelaksanaan program di lapangan. Adapun hasil KKN-BBM ini terentaskannya kebutuhan masyarakat dan meningkatkan pengetahuan masyarakat meskipun, beberapa program kurang maksimal terealisasi di Desa Talun, Kec. Sumberrejo, Kab. Bojonegoro. ${ }^{4}$

5. PkM yang dilakukan oleh Caraka, dkk., berkenanaan dengan pelaksanaan KKN yang memfokus pada program bimbingan belajar pada anak-anak di Miliran RW 02, Kelurahan Muja Muju, menunjukkan hasil bahwa dari program BIMBEL anak-anak antusias dalam mengikuti kegiatan tersebut. Selain itu, program BIMBEL ini juga dapat membantu siswa yang kesulitan dalam mengerjakan soal-soal latihan yang diberikan saat kegiatan pembelajaran di sekolah. ${ }^{5}$

\footnotetext{
${ }^{1}$ Mulasari, S. A., Fatihah, A. N., \& Setiawan, A. (2019). UPAYA PENANGGULANGAN RENTENIR OLEH KULIAH KERJA NYATA UNIVERSITAS AHMAD DAHLAN DI DUSUN KLEPU, NGLEGI, PATUK, GUNUNGKIDUL, DI. YOGYAKARTA 2018. Jurnal Pemberdayaan: Publikasi Hasil Pengabdian Kepada Masyarakat, 2(3), 479-486.

${ }^{2}$ Sapar, S., Munarka, A. H., \& Bustami, L. (2017). Pengabdian KKN-PPM di Desa Lagego Kecamatan Burau Kabupaten Luwu Timur. RESONA: Jurnal Ilmiah Pengabdian Masyarakat, l(1).

${ }^{3}$ Sa'diyah, M., Shita, U., \& SR, F. A. (2018). MENINGKATKAN KUALITAS PENDIDIKAN, KESEHATAN DAN TEKNOLOGI MELALUI PROGRAM KKN TEMATIK DI DESA BOJONG RANGKAS. Abdi Dosen: Jurnal Pengabdian Pada Masyarakat, 2(3).

${ }^{4}$ Kusumawardhani, D. G., Valendra, F. G., Yurika, N., Rahmaniah, A., Khissoga, I. K., Kurniawati, A., \& Yasmin, G. A. (2016). Laporan Akhir KKN-BBM 54 Ds. Talun Kec. Sumberrejo Bojonegoro.

${ }^{5}$ Caraka, P. B., YULITA, Y., Zakilah, Z., MELINDA RUSTANDI, B. E. L. L. A., RISKI LESTARI, F. A. T. L. U., INDAH PERMATASARI TRIYADI, R. I. Y. A., \& AMELIA, P. (2018). Artikel KKN ALTERNATIF, Pemberdayaan Masyarakat Miliran, Muja Muju, Umbulharjo, Yogyakarta, Program Bimbingan Belajar Masyarakat, Divisi III. C. 2 2018. Artikel KKN ALTERNATIF UAD DIVISI III. C. 2 PERIODE 61, 9(1), 1-9.
} 
WAHATUL MUJTAMA': Jurnal Pengabdian Masyarakat

Vol. 1, No. 2 (2020) : Hal. 209-222

Website: https://journal.stiba.ac.id

Berdasarkan hasil-hasil pengabdian masyarakat di atas, maka dalam PkM berwujud KKN angkatan III STIBA Makassar di Desa Alatengae memiliki kesamaa dari segi PkM yang dilangsungkan dalam rangka Kuliah Kerja Nyata. Di antara hasil PkM tersebut persamaan visi pada tujuan pemberdayaan masyarakat, peretasan permasalahan masyarakat, dan upaya solutif melalui pengembangan program KKN. Namun, perbedaan yang belum didapati dari hasi $\mathrm{PkM}$ di atas adalah perancangan program yang dimulai dengan analisis kebutuhan masyarakat, meskipun telah dilakukan oleh Dyah, dkk., akan tetapi belum jelas menggunakan metode analisis.

Berbeda dengan kegiatan KKN yang dilakukan oleh STIBA Makassar di Desa Alatengae. Selain menggunakan instumen atau alat pelacakan problem masyarakat, juga digunakan analisis SOAR sebagai metode dalam strategi penyusunan program KKN. Selain itu, program dijabarkan ke bidang pendidikan, sosial dan kesehatan yang memiliki kekhasan yakni terintegrasi dengan nuansa keagamaan, syariat dan sunah Nabi

\section{PEMBAHASAN}

Bentuk-bentuk kegiatan KKN STIBA Makassar di Desa Alatengae ini terdiri dari beberapa program kegiatan seperti Silaturahim Warga, Pengajaran di SD/TK/TPA, Pengajaran Dirosa, Taklim Muslim dan Muslimah, Tablig Akbar, Seminar Kesehatan dan Bekam, dan Festival Anak Saleh (FAS).

\section{Silaturrahim Warga}

Langkah teknis kegiatan yakni setiap anggota yang tidak memiliki jadwal kegiatan akan berangkat silaturahim. Silaturahim cenderung pada senyuman dan salam kemudian sapaan-sapaan ringan. Pengalaman menarik yang ditemukan adalah warga menerima dengan baik, beberapa juga menyampaikan harapan-harapan dan juga usulan terkait program kerja. Adapun kegiatan ini mendapat dukungan oleh warga Desa Alatengae. Berkenaan silaturrahim, Tullah mengatakan bahwa silaturrahim dapat menumbuhkan nilai-nilai pendidikan karakter yang dapat ditumbuhkan dalam diri pemuda melalui kegiatan silaturrahim dapat ditumbuhkan nilai toleransi, bersahabat, komunikatif, dan peduli sosial. ${ }^{6}$ Dengan demikian, silaturrahim ini juga diekspektasikan untuk menumbuhkan karakter mahasiswa STIBA Makassar.

Kendala pelaksanaan kegiatan ini adalah mahasiswa peserta KKN tidak percaya diri dengan masyarakat setempat. Di samping itu, kurangnya pemahaman bahasa Bugis yang mayoritas dipakai oleh masyarakat Desa Alatengae. Adapun solusinya yang kemudian dilakukan adalah mensosialisasikan program kepada warga setiap kali bertemu atau silaturahim dan bercakap-cakap masalah program KKN STIBA Makassar serta

${ }^{6}$ Tullah, H. (2019). PERAN KEGIATAN SILATURRAHIM DAN QUR'ANAN DALAM MENUMBUHKAN NILAINILAI PENDIDIKAN KARAKTER PEMUDA (STUDI KASUS DI ORGANISASI ALUMNI PROGRAM KEAGAMAAN MAN SURUH) (Doctoral dissertation, IAIN SALATIGA). 
WAHATUL MUJTAMA': Jurnal Pengabdian Masyarakat

Vol. 1, No. 2 (2020) : Hal. 209-222

Website: https://journal.stiba.ac.id

memberdayakan pemuda sekitar sebagai penerjemah bahasa Bugis, alih bahasa Indonesia ke bahasa Bugis pada saat berkomunikasi dengan masyarakat.

\section{Pengajaran di SD dan TK/TPA}

Langkah teknis kegiatan ini yaitu setiap anggota diberikan jadwal yang sudah di sepakati dalam musyawarah antara pihak mahasiswa dengan pihak sekolah, SD/TK/TPA. Adapun setiap SD/TK/TPA yang mengajar berjumlah 2 (dua) mahasiswa KKN STIBA Makassar. Pengalaman menarik yang ditemukan ialah para siswa atau santri bersemangat dan antusias untuk belajar mata pelajaran di luar jadwal sekolah khususnya bahasa Arab. Hal ini dimungkinkan karena jadwal belajar yang masih minim untuk fokus bahasa Arab dengan penyajian metode yang menyenangkan dan sederhana.

Kondisi siswa atau santri sebelum diadakannya kegiatan pengajaran tampak bahwa siswa atau santri kurang mendapatkan pelajaran agama dan cara mengaji yang benar, apatah lagi bahasa Arab. Dengan demikian kondisi setelah kegiatan tampak bahwa siswa atau santri sudah mendapatkan pemahaman tentang Islam dasar dan cara membaca al-Qur'an yang baik dan benar, alih-alih mengetahui sedikit kosa kata bahasa Arab keseharian. Hamdani juga demikian, melalui hasil penelitiannya melalui penerapan metode membaca al-Qur'an pada TPA di Kecamatan Amuntai Utara menunjukkan pengaruh terhadap kemampuan membaca Alquran santri. ${ }^{7}$

Pada kegiatan ini didapati kendala berupa mahasiswa KKN STIBA Makassar diminta mengajar mata pelajaran matematika dan umum yang notabane kurang dikuasai dikarenakan berlatar pendidikan Jurusan perbandingan Mazhab dan Hukum Islam. Kemudian solusi yang diminta kepada pihak sekolah adalah meminta jadwal masuk mata pelajaran agama yang sesuai dengan bidang atau jurusan mahasiswa.

\section{Pengajaran Dirosa (Pembelajaran Al-Qur'an Orang Dewasa)}

Langkah teknis kegiatan ialah dimulai dengan mengadakan sosialisasi kepada masyarakat Desa Alatengae, kemudian dibentuk kelompok belajar masyarakat yang terdiri dari 8-10 orang, dan melanjutkannya dengan pembinaan kepada kelompok belajar Dirosa yang terbentuk tersebut selama 12 (dua belas) kali pertemuan. Pengalaman menarik pada kegiatan ini adalah masyarakat antusias dan menyambut dengan ramah program belajar al-Qur' an khusus dewasa ini. Dengan metode yang sederhana dan praktis kegiatan tersebut sangat didukung oleh masyarakat setempat.

Kondisi sebelum pengajaran Dirosa ialah jumlah SDM (pengajar) Dirosa ditengarai menjadi penyebab turunnya minat belajar mengaji dan memperbaiki bacaan alQur'an, padahal realita yang ditemukan begitu masih banyak mayarakat yang terbata-bata dalam membaca al-Qur'an. Setelah pelaksanaan program kerja ini, masyarakat sudah memahami pelafalan huruf hijaiah yang benar dan makin bertambah peserta dalam

${ }^{7}$ Hamdani, M. (2018). Penerapan Metode Membaca Alquran Pada TPA di Kecamatan Amuntai Utara (Studi pada metode Iqra dan metode Tilawati). Al Qalam: Jurnal Ilmiah Keagamaan dan Kemasyarakatan. 
WAHATUL MUJTAMA': Jurnal Pengabdian Masyarakat

Vol. 1, No. 2 (2020) : Hal. 209-222

Website: https://journal.stiba.ac.id

pembelajaran Dirosa. Masyarakat juga mulai antusias mempelajari al-Qur'an dan juga beberapa lepasan pembinaan pengajaran Dirosa tampak dapat dijadikan sebagai SDM (tenaga pengajar) di Desa Alatengae, tentunya dengan peningkatan dan pengembangan kompetensi melalui pelatihan metode Dirosa. Hal yang serupa juga ditemukan oleh Guswenti melalui penelitiannya menunjukkan bahwa metode Dirosa dapat meningkatkan kemampuan santri orang dewasa di Wahdah Islamiyah. Dalam hal ini dilihat dengan adanya perubahan santri dalam kemampuan membaca al-Qur'an seperti aspek mengenal huruf-huruf hijaiah, makharajul huruf, dan tajwid serta pemahaman dasar-dasar Islam yang menjadi kelebihan metode ini. ${ }^{8}$

\section{Taklim Muslim dan Muslimah}

Langkah teknis program kerja ini ialah dimulai dengan mempersiapkan materi yang praktis dan mudah dipahami serta sesuai dengan kebutuhan masyarakat, kemudian dilakukan upaya pengondisian materi dengan keadaan jemaah. Hal yang menarik dalam pelaksanaan program ini tatkala mahasiswa KKN STIBA Makassar sering mendapatkan jadwal dadakan sehingga dalam menyusun materi dilakukan sembari ketika dzikir dalam waktu yang sesingkat-singkatnya. Walau demikian adanya, antusiasme jemaah di beberapa masjid di Desa Alatengae untuk mendapatkan siraman rohani tetap tinggi dan tanpa peduli lagi atau memikirkan kesiapan penceramah.

Kondisi sebelum taklim muslim dan muslimah tampak kurangnya wawasan keislaman yang dimiliki oleh masyarakat, indikator sederhananya adalah masyarakat belum mampu membedakan mana rukun dan syarat sah salat, demikian juga taharah dan atau wudhu. Setelah berlalunya program kerja tersebut, yang menarik adalah masyarakat meminta agar dilakukan taklim setiap hari, kendati masyarakat pun telah banyak memahami dan semangat serta antusias mempelajari agama. Dari hasil penelitian Muliaty, dkk., ihwal taklim muslimah merekomendasikan agar pengurus majelis taklim al-Mu'minat (komunitas yang diteliti) sebaiknya menggunakan kurikulum dan metode pendidikan Islam yang sesuai dengan kebutuhan jemaah agar menciptakan jemaah yang interaktif, kreatif, inovatif, aktif, dan menyenangkan serta menciptakan masyarakat yang cerdas dan bertakwa kepada Allah 紫.9

Kegiatan ini menuai kendala dari sisi kurangnya kesiapan mahasisiwa dalam masalah materi. Dengan demikian, solusi yang diusahakan adalah mempersiapkan materi jauh hari sebelum waktunya dan menguasai beberapa materi pamungkas, sederhana, praktis, dan mudah dicerna-pahami oleh masyarakat awam.

\section{Tablig Akbar}

\footnotetext{
${ }^{8}$ Guswenti, M. (2019). IMPLEMENTASI METODE DIROSA DALAM PEMBELAJARAN MEMBACA AL-QUR'AN BAGI SANTRI DI WAHDAH ISLAMIYAH BENGKULU (Doctoral dissertation, IAIN BENGKULU).

${ }^{9}$ Amin, M., Marjuni, A., \& Azharia, D. (2018). Gerakan Sosial Keagamaan Masyarakat Perspektif Pendidikan Islam: Majelis Taklim Al-Mu'Minat. Jurnal Aqidah-Ta, 4(2), 149-159.
} 
WAHATUL MUJTAMA': Jurnal Pengabdian Masyarakat

Vol. 1, No. 2 (2020) : Hal. 209-222

Website: https://journal.stiba.ac.id

Langkah teknis program kerja ini yaitu diawali dengan mengadakan rapat koordinasi, lalu mencari dana kegiatan pengadaan proposal, pemanfaatan sosial media, dan networking. Kemudian, dilakukan upaya penyebaran undangan, pamplet dan brosur. Terakhir, menyiapkan dan meminta izin kepada pengurus Masjid Babul Jannah yang akan ditempati tablig akbar. Hal yang menarik tablig akbar bertema "Menggapai Kebahagiaan Dunia Akhirat" ini adalah mahasiswa KKN STIBA Makassar mampu menjalin sinergitas dengan masyarakat dan ormas Wahdah Islamiyah, dari sisi pengadaan tempat dan pemateri.

Selain itu, semangat dan antusias tinggi terlihat dari peserta tablig akbar dalam mengikuti kegiatan. Tampak suasana hidup dan begitu hangat dengan diskusi pemateri dan dua orang peserta tentang pengkajian rezeki. Kondisi sebelum dilaksanakannya tablig akbar bertema "Menggapai Kebahagiaan Dunia Akhirat" terlihat masyarakat sudah beberapa kali mengikuti acara tablig akbar. Namun, setelah berlangsungnya kegiatan, masyarakat umumnya bersemangat sembari menginginkan agar kiranya tablig akbar diadakan tiap pekan. Antusiasme tersebut koheren dengan maksud dan tujuan dari diadakannya kegiatan tablig akbar yakni untuk peningkatan pemahaman keislaman dan kualitas akhlak masyarakat. ${ }^{10}$

Meski demikian, pada acara tersebut ditemukan kendala berupa keterlambatan peserta tablig akbar dan keterlambatan aparat desa. Namun, panitia mengambil langkah inisiatif dengan memanggil secara langsung masyarakat sekitar melalui mikrofon atau pengeras suara (TOA) masjid berupa pengumuman atau mengingatkan. Langkah solutif lainnya adalah dengan membuka acara dengan tokoh masyarakat yang sudah ada di Masjid Babul Jannah.

\section{Seminar Kesehatan dan Bekam}

Langkah teknis pelaksanaan kegiatan ini ialah didahului dengan merancang konsep kegiatan, lalu kemudian menyelesaikan administrasi dan atau persuratan, selanjutnya menentukan penanggung jawab di setiap divisi, dan menyiapkan alat bekam terstandar SNI. Hal yang menarik dari seminar kesehatan dan bekam ini adalah kegiatan sangat didukung oleh Kepala Desa Alatengae. Di lain sisi, masyarakat juga sangat menginginkan dan membutuhkan pengobatan bekam 'Ala Nabi Adapun kegiatan ini dilaksanakan di Masjid Babul Jannah Desa Alatengae.

Gambaran masyarakat sebelum dilaksanakannya agenda seminar kesehatan dan bekam ialah tampak warga merasa kagum dengan seminar kesehatan karena merupakan gebrakan baru selama perhelatan KKN mahasiswa di Desa Alatengae. Dengan demikian, pasca kegiatan warga bersemangat dan antusias dalam menantikan perhelatan seminar kesehatan dan bekam selanjutnya. Hal tersebut lantaran masyarakat telah merasakan manfaat langsung setelah berbekam. Realitas tersebut dibenarkan melalui hasil penelitian

\footnotetext{
${ }^{10}$ Romadi, B., Ma'arif, B. S., \& Thohier, M. (2017). Efektivitas Pelaksanaan Pengajian oleh Yayasan Tarbiyah Sunnah Bandung dalam Peningkatan Akhlak Jamaah.
} 
WAHATUL MUJTAMA': Jurnal Pengabdian Masyarakat

Vol. 1, No. 2 (2020) : Hal. 209-222

Website: https://journal.stiba.ac.id

yang dilakukan oleh Sophi, dkk., ihwal pengaruh bekam di masyarakat Kab./Kota Bandung dalam mana ditemukan bahwa terdapat perbedaan bermakna pada $(\mathrm{p}<0,05)$ antara kondisi kesehatan responden sebelum dan sesudah menjalani terapi bekam terhadap intensitas kualitas tidur, kelelahan, pegal-pegal, dan intensitas sakit. ${ }^{11}$

Adapun Kendala yang ditemukan pada saat diadakannya seminar kesehatan dan bekam terlihat pada keterlambatan peserta dan aparat desa. Langkah solutif dari kendala tersebut ditaktisi dengan memulai acara seminar dengan peserta dan aparat desa yang telah ada.

\section{Festival Anak Saleh}

Festival Anak Saleh (FAS) merupakan kegiatan yang sifatnya perpanjangan tangan (program estafet) dari program pengajaran SD/TK/TPA. Langkah teknis kegiatan FAS ini mula-mula dengan merancang konsep kegiatan, lalu dilanjutkan dengan menyelesaikan administrasi atau persuratan, setelahnya ditentukan penanggung jawab (PJ) di setiap divisi, alih-alih berikutnya mendata calon peserta, dan kemudian melaksanakan kegiatan. Hal unik ditemukan dalam FAS adalah salah satu peserta lomba FAS sangat percaya diri tampil di depan panggung dalam mengumandangkan azan, sampai-sampai salah satu peserta lomba menangis terharu oleh karena kemenangan yang diperolehnya atau keluar sebagai salah satu nominasi juara. Adapun kegiatan ini dilaksanakan di 2 (dua) lokasi yakni di Masjid Babul Jannah dan Masjid Babul Jamaah.

Gambaran peserta atau santri sebelum kegiatan FAS tampak siswa atau santri merasa jenuh dengan kegiatan pembelajaran di sekolah dan TKA/TPA yang monoton serta jarang diselengarakan ajang kompetisi dan pengembangan minat dan bakat. Dengan demikian, hadirnya FAS di Desa Alatengae menjadikan siswa atau santri bersemangat dan juga memiliki antusiasme untuk kemudian mengikuti kegiatan TKA/TPA dan senantiasa melatih kemampuannya, baik pidato, pengetahuan keislaman, tilawah dan hafalan surah. Hal senada juga ditunjukkan oleh Ika \& Nanda melalui hasil pelaksanaan program FAS berupa anak-anak di Dusun Seropan 1 lebih bersemangat dalam mempelajari agama Islam, ${ }^{12}$ kemudian anak-anak juga lebih berani untuk menunjukkan bakat serta rasa percaya dirinya semakin meningkat setelah mengikuti program festival anak saleh. ${ }^{13}$

Kendala yang ditemui dalam penyelenggaraan FAS ini adalah pada saat menjelang FAS terjadi diskomunikasi antara panitia dengan Pemerintah Desa Alatengae

\footnotetext{
${ }^{11}$ Damayanti, S., Muharini, F., \& Gunawan, B. (2012). Profil Penggunaan Terapi Bekam di Kabupaten/Kota Bandung Ditinjau Dari Aspek Demografi, Riwayat Penyakit, dan Profil Hematologi. Acta Pharmaceutica Indonesia, 37(3), 102-109.

${ }^{12}$ Aswar, A., \& Rosmita, R. (2020). Festival Anak Saleh di Desa Leang-leang Kabupaten Maros. WAHATUL MUJTAMA': Jurnal Pengabdian Masyarakat, 1(1), 54-66.

${ }^{13}$ Maryani, I., \& Noveryal, N. (2019). PENYELENGGARAAN FESTIVAL ANAK SHOLEH DI DUSUN SEROPAN I, DESA MUNTHUK, KECAMATAN DLINGO.Jurnal Pemberdayaan: Publikasi Hasil Pengabdian Kepada Masyarakat, 3(2), 131-136.
} 
WAHATUL MUJTAMA': Jurnal Pengabdian Masyarakat

Vol. 1, No. 2 (2020) : Hal. 209-222

Website: https://journal.stiba.ac.id

yang berakibat pada tidak hadirnya pejabat pemerintahan dalam pembukaan acara FAS. Dengan demikian, mahasiswa KKN STIBA Makassar menuai pelajaran dan pengalaman untuk kemudian melakukan evaluasi (rapat internal) berkenaan fiksasi informasi kepada pemerintah setempat sembari meminta maaf ihwal tempat dan waktu pelaksanaan lomba FAS.

\section{KESIMPULAN}

Tujuan dari pelaksanaan pengabdian kepada masyarakat berwujud KKN angkatan III STIBA Makassar di Desa Alatengae yaitu:

1. Mengaktualisasikan hasil belajar mahasiswa di masyarakat luas.

2. Memberikan kontribusi riil kepada masyarakat sebagai wujud realisasi pengamalan pilar tri dharma perguruan tinggi.

3. Menjadi ajang belajar dan evaluasi diri bagi mahasiswa dalam menghadapi dunia dakwah yang sesungguhnya.

4. Menjadi bahan evaluatif bagi STIBA Makassar dalam berbenah dan meningkatkan kualitas lulusan.

Hasil dari pelakanaan PkM berwujud KKN ini ialah pada umumnya masyarakat setempat mengalami perkembangan dari sisi pengetahuan keislaman, antusias dalam mempelajari dan telah mampu membaca al-Qur'an dengan baik dan benar, dan tumbuhnya kepercayaan diri pada diri santri TK/TPA dalam berkompetisi dan antusiasme yang tinggi pada peningkatan minat dan bakat.

\section{Saran Keberlanjutan program kegiatan (FOLLOW UP):}

\section{Pengajaran Dirosa}

a. Dilakukan upayang pengkaderan peserta dirosa yang telah menyelesaikan masa belajar dan telah diwisuda.

b. Mengkoordinir jalannya Dirosa dengan membuat grup whatsapp khusus.

c. Memantau perkembangan peserta dirosa dengan menghubungi via telepon jika memungkinkan.

d. Mahasiswa selaku mentor Disrosa diharapkan untuk menyempatkan datang langsung mengevaluasi lepasan atau alumni pengajaran Dirosa.

2. Pengajaran SD dan TKA/TPA

a. Mengusulkan pengangkatan guru agama yang berkonsentrasi di bidang pendidikan agama Islam (PAI).

b. Pemetaan kelas belajar TKA/TPA, sesuai tingkatan kemahiran santri sehingga lebih fokus dalam pembelajaran.

3. Kajian Muslim dan Muslimah

a. Mengadakan pengajian rutin dengan menetapkan jadwal tertentu.

b. Mengusahakan mengundang ustadz dan dai yang pakar dan terkenal. 
WAHATUL MUJTAMA': Jurnal Pengabdian Masyarakat

Vol. 1, No. 2 (2020) : Hal. 209-222

Website: https://journal.stiba.ac.id

\section{DAFTAR PUSTAKA}

Amin, M., Marjuni, A., \& Azharia, D. (2018). Gerakan Sosial Keagamaan Masyarakat Perspektif Pendidikan Islam: Majelis Taklim Al-Mu'Minat. Jurnal AqidahTa, 4(2), 149-159.

Aswar, A., \& Rosmita, R. (2020). Festival Anak Saleh di Desa Leang-leang Kabupaten Maros. WAHATUL MUJTAMA': Jurnal Pengabdian Masyarakat, 1(1), 54-66.

Caraka, P. B., YULITA, Y., Zakilah, Z., MELINDA RUSTANDI, B. E. L. L. A., RISKI LESTARI, F. A. T. L. U., INDAH PERMATASARI TRIYADI, R. I. Y. A., \& AMELIA, P. (2018). Artikel KKN ALTERNATIF, Pemberdayaan Masyarakat Miliran, Muja Muju, Umbulharjo, Yogyakarta, Program Bimbingan Belajar Masyarakat, Divisi III. C. 2 2018. Artikel KKN ALTERNATIF UAD DIVISI III. C. 2 PERIODE 61, 9(1), 1-9.

Damayanti, S., Muharini, F., \& Gunawan, B. (2012). Profil Penggunaan Terapi Bekam di Kabupaten/Kota Bandung Ditinjau Dari Aspek Demografi, Riwayat Penyakit, dan Profil Hematologi. Acta Pharmaceutica Indonesia, 37(3), 102-109.

Guswenti, M. (2019). IMPLEMENTASI METODE DIROSA DALAM PEMBELAJARAN MEMBACA AL-QUR'AN BAGI SANTRI DI WAHDAH ISLAMIYAH $B E N G K U L U$ (Doctoral dissertation, IAIN BENGKULU).

Hamdani, M. (2018). Penerapan Metode Membaca Alquran Pada TPA di Kecamatan Amuntai Utara (Studi pada metode Iqra dan metode Tilawati). Al Qalam: Jurnal Ilmiah Keagamaan dan Kemasyarakatan.

Kusumawardhani, D. G., Valendra, F. G., Yurika, N., Rahmaniah, A., Khissoga, I. K., Kurniawati, A., \& Yasmin, G. A. (2016). Laporan Akhir KKN-BBM 54 Ds. Talun Kec. Sumberrejo Bojonegoro.

Maryani, I., \& Noveryal, N. (2019). PENYELENGGARAAN FESTIVAL ANAK SHOLEH DI DUSUN SEROPAN I, DESA MUNTHUK, KECAMATAN DLINGO. Jurnal Pemberdayaan: Publikasi Hasil Pengabdian Kepada Masyarakat, 3(2), 131-136.

Mulasari, S. A., Fatihah, A. N., \& Setiawan, A. (2019). UPAYA PENANGGULANGAN RENTENIR OLEH KULIAH KERJA NYATA UNIVERSITAS AHMAD DAHLAN DI DUSUN KLEPU, NGLEGI, PATUK, GUNUNGKIDUL, DI. YOGYAKARTA 2018. Jurnal Pemberdayaan: Publikasi Hasil Pengabdian Kepada Masyarakat, 2(3), 479-486.

Profil Desa Alatengae Tahun 2019. 
WAHATUL MUJTAMA': Jurnal Pengabdian Masyarakat

Vol. 1, No. 2 (2020) : Hal. 209-222

Website: https://journal.stiba.ac.id

Sapar, S., Munarka, A. H., \& Bustami, L. (2017). Pengabdian KKN-PPM di Desa Lagego Kecamatan Burau Kabupaten Luwu Timur. RESONA: Jurnal Ilmiah Pengabdian Masyarakat, 1(1).

Sa'diyah, M., Shita, U., \& SR, F. A. (2018). MENINGKATKAN KUALITAS PENDIDIKAN, KESEHATAN DAN TEKNOLOGI MELALUI PROGRAM KKN TEMATIK DI DESA BOJONG RANGKAS. Abdi Dosen: Jurnal Pengabdian Pada Masyarakat, 2(3).

Tullah, H. (2019). PERAN KEGIATAN SILATURRAHIM DAN QUR'ANAN DALAM MENUMBUHKAN NILAI-NILAI PENDIDIKAN KARAKTER PEMUDA (STUDI KASUS DI ORGANISASI ALUMNI PROGRAM KEAGAMAAN MAN SURUH) (Doctoral dissertation, IAIN SALATIGA). 